\title{
Advanced Primary Care in San Antonio: Linking Practice and Community Strategies to Improve Health
}

\author{
Robert L. Ferrer, MD, MPH, Carolina Gonzalez Schlenker, MD, MPH, \\ Raquel Lozano Romero, MD, MPH, Ramin Poursani, MD, Oralia Bazaldua, PharmD, \\ DeWayne Davidson, PharmD, Melissa Ann Gonzales, RN, Janie DeHoyos, RN, \\ Martha Castilla, CHW, Betty A. Corona, FNP, James Tysinger, PhD, \\ Bryan Alsip, MD, MPH, Jonathan Trejo, BA, and Carlos Roberto Jaén, MD, PhD
}

Improving health among people living in poverty often transcends narrowly focused illness care. Meaningful success is unlikely without confronting the complex social origins of illness. We describe an emerging community of solution to improve health outcomes for a population of 6000 San Antonio, Texas, residents enrolled in a county health care program. The community of solution comprises a county health system, a family medicine residency program, a metropolitan public health department, and local nonprofit organizations and businesses. Community-based activities responding to the needs of individuals and their neighborhoods are driven by a cohort of promotores (community health workers) whose mission encompasses change at both the individual and community levels. Centered on patients' functional goals, promotores mobilize family and community resources and consider what community-level action will address the social determinants of health. On the clinical side, care teams implement population-based risk assessment and nurse care management with a focus on care transitions as well as other measures to meet the needs of patients with high morbidity and high use of health care. Population-based outcome metrics include reductions in hospitalizations, emergency department and urgent care visits, and the associated charges. Promotores also assess patients' progress along the trajectory of their selected functional goals. (J Am Board Fam Med 2013;26:288-298.)

Keywords: Community Medicine, Delivery of Health Care, Primary Health Care

Drawing on his pioneering work in neighborhood health centers in South Africa during the 1940s, Sydney Kark later wrote that "The main factors that determine a community's health are to be found within the community itself, in its social,

This article was externally peer reviewed.

Submitted 1 September 2012; revised 23 January 2013; accepted 4 February 2013.

From the ${ }^{1}$ Department of Family and Community Medicine, University of Texas Health Science Center at San Antonio (RLF, CGS, RLR, RP, OB, DD, MC, BAC, J. Tysinger, J. Trejo, CRJ); and the ${ }^{2}$ University Health System, San Antonio, TX (MAG, JD, BA).

Funding: Funding for this project was provided by the University Health System, San Antonio, TX.

Conflict of interest: none declared.

Corresponding author: Robert Ferrer, MD, MPH, Department of Family and Community Medicine, University of Texas Health Science Center at San Antonio, 7703 Floyd Curl Drive, San Antonio, TX 78229-3900 (E-mail: FerrerR@uthscsa.edu). biological or cultural features, or in its environment, natural and man-made." 1 The title of that paper was itself instructive, "From Medicine in the Community to Community Medicine," capturing a philosophical and logistic transition with which health care continues to struggle. ${ }^{2}$

Most current primary care reform models, although important guideposts for needed change, remain constricted versions of the transformative prototypes designed by Kark and others that followed, among them Jack Geiger working in the Mississippi delta. Geiger articulated well the aspirations of that era: " $[\mathrm{H}]$ ealth services, which have sanction from the larger society and salience to the communities they serve, have the capacity to attack the root causes of ill health through community development and the social change it engenders." 
By the 1960s the social medicine movement had built enough momentum to set the stage for the ambitious Folsom Report ${ }^{2,4}$ and its even more muscular successor, the Declaration of Alma Ata (1978). ${ }^{5}$ The delegates at Alma Ata imagined primary health care at the center of a health-sustaining collaboration encompassing education, housing, food, public works, communications, and other sectors.

This coordinated approach to social determinants proved to be neither politically feasible in market economies nor professionally palatable to a rapidly specializing health care workforce ${ }^{6}$ Instead, notwithstanding the limited community-oriented primary care movement, ${ }^{7}$ primary care evolved largely as a clinical service true to its generalist roots but engaged little with the community origins of health and illness. This remains the prevailing orientation today as the "medical neighborhood" is invoked in patient-centered medical home (PCMH) models mainly to highlight aspects of coordinating specialist and ancillary services. ${ }^{8}$ Early evidence from PCMH demonstrations shows that coordinating with external resources remains challenging for many practices and is a contributing factor when results fall short of expectations. ${ }^{9}$ Still, there are encouraging pockets of success ${ }^{10,11}$ and growing recognition that primary care and public health need to be closely integrated to achieve their shared mission of better population health. ${ }^{12}$

In this article we describe an emerging community of solution (CoS) addressing the health of a disadvantaged, largely Latino population in San Antonio, Texas. The CoS brings together a county health district, a metropolitan health department, and an academic department of family medicine. Primary care-based improvements for a defined population are linked with community-based promotores with the explicit goal of addressing both individual health and community determinants.

\section{Population and Setting}

Our population is a panel of approximately 6000 uninsured patients assigned to our family health center for primary care services. Their care is funded by CareLink, a program supported by county property taxes, administered by the Bexar County Hospital District (BCHD, dba University Health System) a political subdivision of Texas. Created in 1955 by state-wide vote on an amend- ment to the state's constitution, the hospital district's purpose is to provide health care to indigent Bexar County residents. Those who can document county residence, financial need, and a source of monthly income are eligible to enroll; U.S. citizenship is not required. Members receive ambulatory and hospital care, preventive services, and formulary medications. Charges are discounted and billed in monthly installments on a sliding scale determined by income.

Our "Advanced Primary Care" project was made possible by a contract from BCHD to our Department of Family and Community Medicine, which operates an urban safety net clinic and receives 45,000 visits each year. It is also the primary teaching site for a 36-resident family medicine program. The contract is contingent on achieving and maintaining specific goals (eg, 10\% reduction in hospital and emergency department [ED] visits and the associated charges). As the purchaser of health services for our panel, the BCHD's motivation was to improve its patients' health while reducing costs from preventable morbidity. After a preliminary pilot with a smaller cohort demonstrated promising results in 2011, the project began in February 2012.

Bexar County itself, located in south-central Texas, is home to 1.71 million residents (2011 Census estimates), of whom 1.32 million reside within the City of San Antonio. The county is characterized by high rates of poverty $(17 \%)$ and uninsurance (22.8\%). Deep socioeconomic and health disparities divide the county. For example, $92.9 \%$ of the Northeast sector's adults earned a high school diploma compared with only $54.5 \%$ of those in the South sector. Preventable years of life lost are twice as high in the South sector. ${ }^{13}$

As we examined the cohort's morbidity and use of health care services, we noted that many highmorbidity, high-use patients were concentrated in 6 ZIP codes around our health center (Figure 1). We therefore decided to construct our $\mathrm{CoS}$ for maximum relevance to those 6 ZIP codes, consulting with community health workers who were familiar with the relevant neighborhoods.

\section{Program Goals}

Our goal is to improve health outcomes and reduce costs due to preventable morbidity by attending not only to the well-being of individual patients but also to the social determinants of health in our popula- 
Figure 1. Map of Bexar County, which contains the city of San Antonio, identifying the 6 priority ZIP codes and the location of our family health center. Each ZIP code is identified on the map by its final 2 digits; the full 5-digit ZIP codes appear at bottom right.

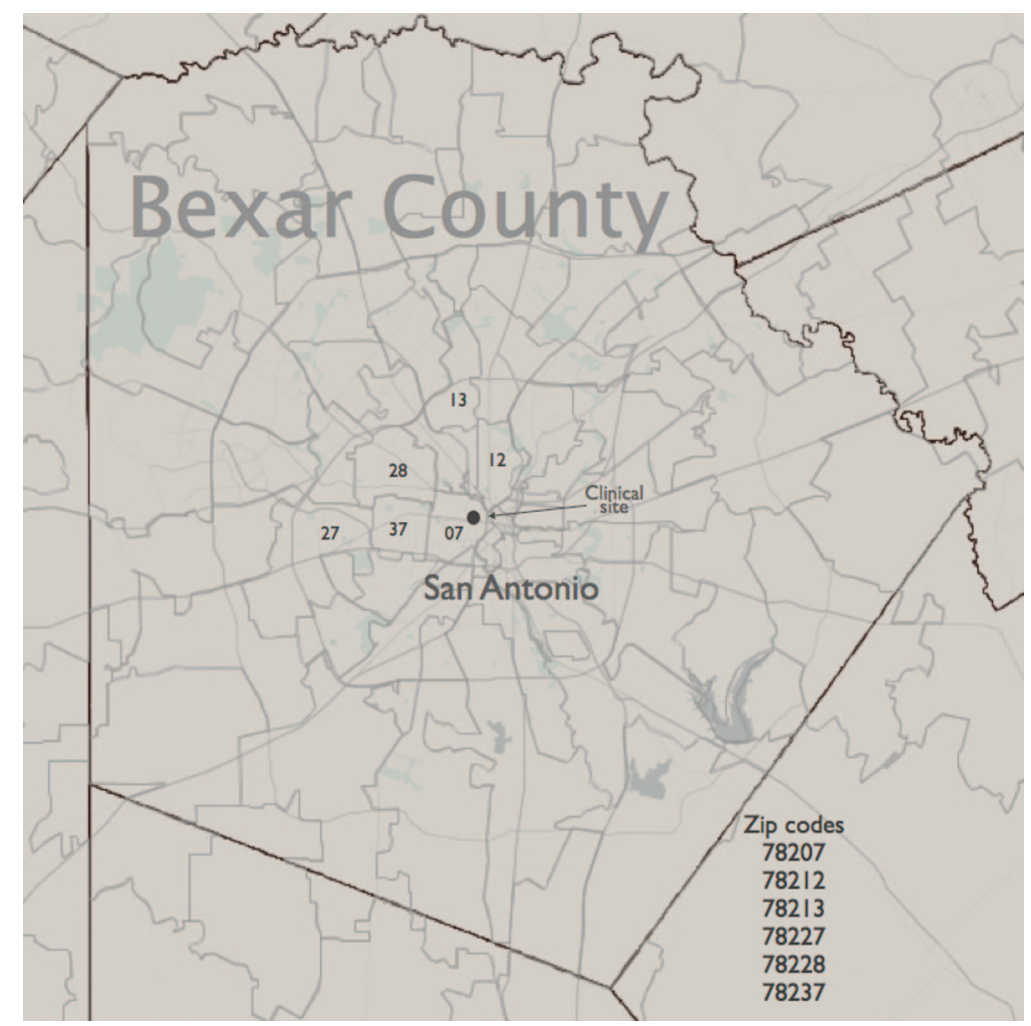

tion's communities. Achieving both goals requires a set of linked community and health care activities that we will describe more fully below. The following general principles guide our approach:

1. Focus on patient-centered outcomes. Although the metrics in our contract focus on health care utilization, we designed our interventions so that patients' functional goals would be a chief objective. $^{14,15}$

2. A set of intensive care management activities is necessary to improve outcomes for the patients with the highest needs. ${ }^{16}$

3. Systemic improvements in access and personalized team care for all patients will improve the patient experience and influence outcomes across the entire patient panel. ${ }^{17}$

4. Finding and mobilizing community resources is necessary to overcome the health care system's limited ability to solve important problems in patients' lives. ${ }^{18}$

On the clinical side, the challenge was less to invent new approaches than to implement recog- nized strategies effectively: improve access, identify and respond to sentinel events (ED and hospital visits), improve care transitions, and develop systems to promote effective self-management. On the community side, how to operationalize an effective approach to social determinants within the scope and budget of our project was less clear. We sought a $\mathrm{CoS}$ that would encompass primary care, public health, community groups, nonprofits, and businesses in the 6 ZIP codes. The mechanism we chose to drive the $\mathrm{CoS}$ was community health workers-promotores-working with an expanded focus. Although experience with employing promotores to extend the reach of health services has been growing, ${ }^{19}$ they often are called on to deliver services tailored to a disease focus. ${ }^{20,21} \mathrm{We}$ formulated the promotore role differently: to encompass a mission of both individual and community-level change. That is, promotores combine direct patient services with community-level work in their ZIP codes. In this way, promotores become the conduits for a bidirectional flow of knowledge and action: knowledge of community flowing down to improve 
the relevance and scope of individual patient care, and knowledge of individual patients aggregated to reveal assets or areas of unmet needs that could trigger community-level action.

Our program objectives address several of the grand challenges from the new Folsom Report ${ }^{2}$ :

1. The ongoing development of integrated, comprehensive practices accessible for all groups in a community.

2. Provide every individual in the United States the opportunity to form a partnership with a personal physician and a team of health professionals offering integrated community health services.

3. Integrate health services-aligning hospital, ambulatory, and community care-across settings to promote quality and create value.

\section{A Promotore Model to Promote Individual and Community Health}

The promotore-patient interaction focuses on patients' functional status. This approach is formalized using the World Health Organization's International Classification of Functioning, Disability, and Health (ICF) ${ }^{22}$ to set goals and measure progress. The ICF is a taxonomy of body structures and functions, activities and participation, and environmental factors (Table 1). We chose the ICF for several reasons. First, it is holistic enough to capture the relevant domains of illness, functional sta-

Table 1. Table of Classifications in Activities and Participation Component and Environmental Component of International Classification of Functioning, Disability, and Health

\begin{tabular}{|c|c|}
\hline Activities and Participation & Environmental Factors \\
\hline $\begin{array}{l}\text { Learning and applying } \\
\text { knowledge }\end{array}$ & Products and technology \\
\hline General tasks and demands & $\begin{array}{l}\text { Natural environment and } \\
\text { human-made changes }\end{array}$ \\
\hline Communication & Support and relationships \\
\hline Mobility & Attitudes \\
\hline Self-care & Services, systems, and policies \\
\hline \multicolumn{2}{|l|}{ Domestic life } \\
\hline \multicolumn{2}{|l|}{$\begin{array}{l}\text { Interpersonal interactions and } \\
\text { relationships }\end{array}$} \\
\hline \multicolumn{2}{|l|}{ Major life areas } \\
\hline $\begin{array}{l}\text { Community, social, and civic } \\
\text { life }\end{array}$ & \\
\hline
\end{tabular}

tus, and social determinants. Second, it provides a mechanism to understand and evaluate promotores' work within an overall approach centered on function rather than disease. ${ }^{23}$ Third, aggregating the assessments for patients within a community, especially the ratings of contextual factors, will provide data about community-level assets and needs that influence health outcomes.

We developed a set of training materials and exercises to introduce the ICF to the promotores. ICF coding is done in partnership with patients to arrive at a goal-oriented statement ${ }^{24}$ of their current priorities for action. The patient's capacity to carry out meaningful roles thus becomes the objective of the patient:promotore relationship. Promotores coach patients to consider how their health care relates to their goals, for example, how selfmanagement can reduce disabilities that interfere with functional goals, or how patients can talk with their clinicians about rebalancing clinical and personal priorities. In this manner, health care protocols become linked to patients' functional status.

Promotores begin with the premise that trusting relationships form the core of work with patients and communities. ${ }^{25}$ Based on theory and methods of ethnomethodology ${ }^{26}$ and discourse analysis, ${ }^{27,28}$ we propose as our trust unit an intersubjective event called nosotros (Spanish for "we"). A nosotros is a moral encounter, a trust unit built when those who are face to face achieve a verbalized, shared perspective ("true" outcome) and an acted, joint production ("good" outcome), both of which emerge from each person's unique contribution to the dyad. Participants in a nosotros answer 2 sequential questions: What do we want to happen? and, What were we able to do? The first question develops a mutual understanding of problems and contexts, whereas the second records the results of the agreed on action plan.

By coding outcomes of the trust unit between the promotore and the patient, we seek to decrease the patient's experience of uncertainty and misinformation when managing complex chronic disease. Promotores use illustrations of the ICF $\operatorname{codes}^{29}$ and a condensed ICF manual during their encounters to look up, with the patient's participation, the appropriate codes for labeling the 2 outcomes of their nosotros. The worksheet used by promotores to code their patient encounters is displayed in Table 2. At each visit, patients receive a summary of the ICF discussion and decisions. 
Promotores' periodic interactions with patients become a series of steps that define and achieve desired outcomes. However, we expect the outcomes to be contingent on, or aimed at, people and resources in the larger society who are not present during the promotore-patient meetings. These relationships are explored through an ecomap, a genogram that also considers connections to the broader community.

Primary care clinicians often consider patients to be struggling when the patients' adherence to care protocols is poor and they use health services inappropriately. Many times, however, the care provided is inaccessible, fragmented, and confusing. Part of the promotores' role is to help mediate a mutual understanding between patients and clinical teams. Therefore, promotores, clinical teams, and patients come together at group visits.

Group visits are held at the primary care clinic and are relaxed, extended encounters that seek to understand the patients' perspective in their selfcare. Clinical team members adjust existing protocols to optimize care delivery, gain insights into their patients' functioning, and account for social determinants. Professional team members include the nurse care manager, pharmacists, social workers, physicians, and representatives from the county health plan.

As described earlier, our target area includes 6 ZIP codes in San Antonio. Several organized efforts are underway in local government, academic centers, and nonprofit agencies to address disparities affecting these ZIP codes. Promotores, who live in those ZIP codes, understand and experience the conditions in their neighborhoods and work to ameliorate their negative effects.

Community understanding is built by creating maps. A San Antonio city planner working with our team created detailed, poster-sized maps of each ZIP code that were populated with physical and administrative features from the city's geographic information system. Promotores augmented the maps with labeled pins marking other features they discovered. Unexpected discoveries arose, including the presence of 82 churches in just one ZIP code. Examples of community partners engaged by the promotores appear in Table 3.

As promotores evaluate patients' resource needs, they ask 3 questions in sequence, assigning ICF environmental factors codes at each level: What product or resource is necessary? What kind of entity will provide it (eg, specific business or nonprofit, available locally or not)? What sector of society is represented (eg, transportation, utilities, food)? Using this system will create an accounting of what flows of assets and services occur through what local agencies/businesses to meet what local needs. Beyond that, mapping and examining resource flows transform the abstract notion of social determinants into a tangible web of policies, organizations, agents, and resources.

In addition to the mapping initiative, we also have been collaborating on areas of mutual interest with chronic disease prevention program of our municipal health department. An early shared activity was for promotores and public health personnel to train together in the Stanford self-management education program. ${ }^{30}$

\section{Transforming the Clinical Endeavor}

The set of changes we are pursuing in our clinical practice address many elements included in current PCMH models, ${ }^{31}$ including enhanced access, nurse care management, on-site pharmacy consultation, and coordination of care transitions (Table 4). We identify high-risk patients who need more intensive services from monthly utilization reports. These patients are mailed cards identifying them as members of our Advanced Primary Care project and letters explaining the available services, and they are invited to group visits.

An experienced practice facilitator ${ }^{32,33}$ helps to assess practice performance from the patient perspective. Several early assessments revealed that the clinical team's assumptions about how the system works for patients often were incorrect. These eyeopeners motivated us to test assumptions directly, for example, that a particular phone line will be answered or that a prescription can be filled at a certain site.

We also have applied this kind of inquiry to our internal processes. To help staff fully understand the challenges of fulfilling each role within the practice, we use role playing exercises that illuminate each step of a patient's journey from appointments to registration to discharge. These exercises reveal inefficiencies and competing demands. The goal is to build an internal CoS dedicated to excellent patient experience. 


\section{Table 2. Worksheet Used by Promotores to Code Their Patient Encounters}

Instructions: Using your Presencia Viva ICF cards, reflect on what you know about the patient. Review the ICF domains in the form and write a sentence that captures what happened in the Nosotros story under the appropriate subdomain. Check a qualifier (impairment, functional or flourishing) that best describes the patient's current state. Be ready to share the story behind your coding. Code only what is touched by the story. Use your little ICF book to find more specific codes if needed.

\begin{tabular}{|c|c|c|c|c|}
\hline Domain & Subdomains & Impairment (1-4) & Functional & Flourishing \\
\hline $\begin{array}{l}\text { d1 Learning and practicing } \\
\text { what was learned }\end{array}$ & $\begin{array}{l}\text { d11. Paying attention with the senses } \\
\text { d13. Basic learning } \\
\text { d16. Putting to practice what was learned }\end{array}$ & & & \\
\hline $\begin{array}{l}\text { d2 General tasks and } \\
\text { demands }\end{array}$ & $\begin{array}{l}\text { d22. Carrying out tasks } \\
\text { d23. Making plans and completing them } \\
\text { d24. Handling stress }\end{array}$ & & & \\
\hline d4 Mobility & $\begin{array}{l}\text { d41. Changing body position } \\
\text { d42. Transferring oneself } \\
\text { d43. Lifting and carrying objects } \\
\text { d44. Fine hand use } \\
\text { d45. Walking } \\
\text { d46. Moving around in different locations } \\
\text { d465. Moving around using equipment } \\
\text { d47. Using transportation } \\
\text { d475. Driving }\end{array}$ & & & \\
\hline d5 Self-care & $\begin{array}{l}\text { d51. Washing one self } \\
\text { d52. Caring for body parts } \\
\text { d53. Toileting } \\
\text { d54. Dressing } \\
\text { d55. Eating } \\
\text { d56. Drinking } \\
\text { d5700. Ensuring one's physical comfort (link to } \\
\text { zoom-in) } \\
\text { d5701. Managing diet and fitness } \\
\text { d5702. Maintaining one's health (link to clinical } \\
\text { care) }\end{array}$ & & & \\
\hline d6 Domestic life & $\begin{array}{l}\text { d61. Acquiring a place to live } \\
\text { d62. Acquiring products and services for daily living } \\
\text { d63. Preparing meals } \\
\text { d64. Doing housework } \\
\text { d65. Caring for household objects } \\
\text { d56. Assisting others }\end{array}$ & & & \\
\hline d8 Major life areas & $\begin{array}{l}\text { d81.Informal education } \\
\text { d82. School education (up to high school) } \\
\text { d83. Higher education } \\
\text { d84. Work preparation, apprenticeship } \\
\text { d845 Getting, keeping and terminating a job } \\
\text { d850. Paid employment part or full time } \\
\text { d855. Work without pay } \\
\text { d860. Basic economic transactions } \\
\text { d865. Complex economic transactions } \\
\text { d8700. Personal economic self-sufficiency } \\
\text { d8701. Public economic entitlements }\end{array}$ & & & \\
\hline $\begin{array}{l}\text { d9 Community, social and } \\
\text { civic life }\end{array}$ & $\begin{array}{l}\text { d9100. Informal associations } \\
\text { d9101. Formal associations (unions, professional, } \\
\text { etc.) } \\
\text { d9102. Ceremonies }\end{array}$ & & & \\
\hline
\end{tabular}


Instructions: Using your Presencia Viva ICF cards, reflect on what you know about the patient. Review the ICF domains in the form and write a sentence that captures what happened in the Nosotros story under the appropriate subdomain. Check a qualifier (impairment, functional or flourishing) that best describes the patient's current state. Be ready to share the story behind your coding. Code only what is touched by the story. Use your little ICF book to find more specific codes if needed.

\begin{tabular}{|c|c|c|c|c|}
\hline Domain & Subdomains & Impairment (1-4) & Functional & Flourishing \\
\hline & d9200. Play & & & \\
\hline & d9201. Sports & & & \\
\hline & d9202. Arts and culture & & & \\
\hline & d9203. Crafts & & & \\
\hline & d9204. Hobbies & & & \\
\hline & d9205. Socializing & & & \\
\hline & d9300. Organized religion & & & \\
\hline & d9301. Spirituality & & & \\
\hline & d940. Human rights & & & \\
\hline & d950. Political life and citizenship & & & \\
\hline
\end{tabular}

ICF, International Classification of Functioning, Disability, and Health.

\section{Process and Outcomes Measurement}

The evaluation of our 2011 pilot project, which focused on managing hospital discharge transitions and improving patient access, compared 2011 ED visits and admissions with 2010 baseline values in a cohort of 1500 high-use patients. Among the 1034 patients who remained in the cohort at the end of the project, there was a $24 \%$ decrease in hospitalizations, a $12 \%$ increase in $\mathrm{ED}$ visits, and a $9 \%$ decrease in total charges, for an annualized overall savings of \$250,215 compared with 2010. This was a limited evaluation, lacking a control group and subject to regression to the mean for patients initially selected for high spending and utilization.

The evaluation for our 2012 project specified population metrics for the whole panel, including hospitalizations and ED and urgent care visits per 1000 enrolled and the associated charges. The target was a $10 \%$ reduction in each category for 2012 compared with 2011 baselines.
Data for each utilization outcome appear in Figure 2, displayed as run charts for monthly performance beginning January 2011 and ending March 2013. The charts display considerable month-to-month volatility, as would be expected with small numerators. Nevertheless, the data point to success in re-engaging panel patients visiting urgent care. There are also trends in the last six months of the project, when all components were fully operational, toward decreased hospital admissions and emergency department visits.

Another evaluation mechanism we have developed is to examine the trajectory of patients' functional status as they work with promotores. Written records of patients' functional goals, action steps taken, and their progress with functional status will provide both process and patient outcome data for the promotores' efforts. An example illustrating this functional assessment and tracking appears in the Appendix.

Table 3. Community Agencies Engaged by Promotores

\begin{tabular}{|c|c|c|c|}
\hline Government & Faith-Based & Nonprofit & For-profit \\
\hline Bexar County Agency on Aging & Blessed Sacrament Catholic Church & Alamo Area Resources & Apartment Wiz \\
\hline Bexar County City Public Services & $\begin{array}{l}\text { Catholic Counseling and } \\
\text { Consultation Center }\end{array}$ & Avanza Community Center & AQTS-Home Health \\
\hline $\begin{array}{l}\text { City of San Antonio Department of } \\
\text { Community Initiatives }\end{array}$ & $\begin{array}{l}\text { Catholic Charities Crisis } \\
\text { Intervention Center }\end{array}$ & $\begin{array}{l}\text { Heart for the } \\
\text { Neighborhood }\end{array}$ & $\begin{array}{l}\text { Medical Solutions, } \\
\text { Inc. }\end{array}$ \\
\hline Edgewood School District & Holy Spirit Catholic Church & Helping Hands Lifeline & \\
\hline San Antonio Housing Authority & Salvation Army & Texas Diabetes Institute & \\
\hline Mexican Consulate & $\begin{array}{l}\text { San Antonio Methodist Ministries } \\
\text { Transitional House }\end{array}$ & & \\
\hline University Health System & Jewish Family Counseling Center & & \\
\hline
\end{tabular}


Table 4. Advanced Primary Care Components in Clinical Improvement Initiatives

Identification of high-morbidity, high-need patients; medical record review

Patients invited to participate in multidisciplinary group visits, assembled by ZIP code

Nurse care management

Pharmacist review for high-morbidity patients; also trigger of 10 or more meds

Care transition management for hospital and emergency department visits

Targeted patient experience surveys to determine chief reasons for visits to emergency department and urgent care center

Process improvements to patient flow through family health center

Process improvements in patient telephone access

Education and assistance with maintaining health plan enrollment

Close integration of practice clinicians with advanced primary care project initiatives

Group visits for patients with intense medical and social needs

\section{Challenges}

As an emerging $\mathrm{CoS}$ pushing against the status quo, we face several hurdles. The sheer number of change initiatives within our clinical system stretches thin our improvement team and challenges the institutional partners we depend on to help implement the changes. Transforming the practice also involves changing the behavior of 50 part-time clini- cians in a relatively resource-poor setting. There is the added structural problem of mixed leadership because clinicians and support staff work for different organizations. In addition, the marriage of clinical and community approaches, with their different world views and timelines, means that even the core implementation team is sometimes tested in its ability to reach consensus. This has triggered spirited discussions about how to sequence and prioritize different components of the initiative. Yet the team's focus on meeting the needs of our population maintains an underlying unity.

As we care for that population, we are mindful of the need to balance 2 concerns: the number of people reached and the intensity of help offered. We are evaluated on the health services experience of 6000 patients but are mindful that a small fraction account for the majority of the hospitalizations and costs. One illustration is the scores of hours a promotora recently spent assembling resources to avert the shut-off of utilities or eviction of a patient on ambulatory peritoneal dialysis; his alternative was homelessness.

Timely information fuels improvement, and we struggle to obtain it from systems that are not designed to move data to the front lines of care. For example, active management of care transitions requires real-time information on hospital admissions and $\mathrm{ED}$ visits to be directed to the appropriate

Figure 2. Project outcomes in 2011 to 2012, displaying run charts for rates of hospital admissions (top left), emergency department visits (bottom left), and urgent care visits (top right) for each month from January 2011 through November 2012. The panel on the bottom right displays the monthly panel size during various intervals.

\section{Utilization outcomes}
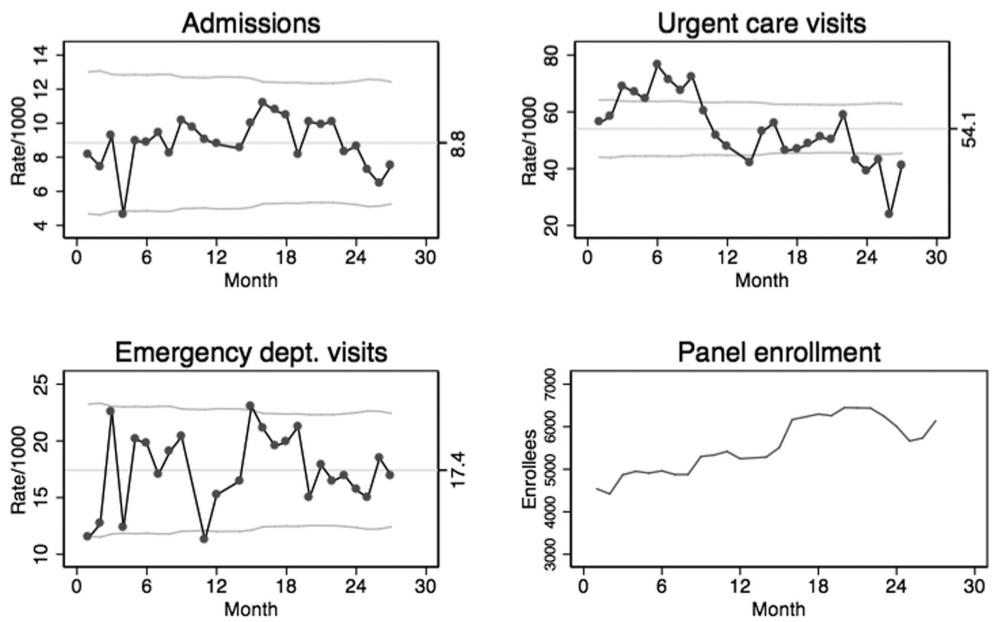

Jan 2011 to March 2013. Monthly rates per 1000 enrollees. Right axes show median rates. 
clinicians. Solutions sometimes have entailed laborious workarounds, such as the daily scanning of visit logs from a very busy ED to find the handful of patients from our center.

A deeper challenge is that incentives are not aligned throughout our clinical system. Our project is evaluated on population-level outcomes while individual departments (including ours) within our clinical enterprise continue to be judged by the relative value units they generate. This leads to contradictions even within the same institution, for example, when the responsibility of one subunit is to reduce utilization while another's interests lie in maximizing it.

An evaluation issue is how to account for the monthly turnover in our cohort, which averages 6\% to $8 \%$. Because new county health plan members often enroll after they become ill there is adverse selection, with high initial health care utilization.

Finally, many key program components, including nurse care management and promotores services required several months to recruit, hire, and train new personnel as well as implement new processes; the full program thus has been active for just 6 months. As we examine project outcomes, we recognize that longer time frames often are needed to see results. ${ }^{34}$

\section{Conclusion}

We are assembling a CoS to improve the health of an economically disadvantaged urban population. Our goal is not only to improve the health of our patient population, but to address the contextual factors driving health in their neighborhoods. The work thus far has led us to several early conclusions. First, feedback from patients participating in our expanded services makes it plain that they deeply value the extra time and assistance. Attention is the currency of primary care and we can now offer more channels of attention-care management, group visits, community health workers-tailored to patients' needs. Second, the things we do not know sabotage us every day. Often, we do not understand enough about patients' lives to be solving the right problems. Each promotore home visit to our sickest patients yields critical information. Other times, we do not understand enough about the de facto workings of our own health system to guide patients appropriately. Coordinated and directed teamwork, with adequate resources to accomplish the task, is essential to discover and unearth vital information. Third, there are many partners willing to engage with us. Adopting a CoS mindset, and approaching nontraditional partners, has led to meaningful changes. Fourth, promotores appreciate being able to apply their skills more holistically, considering patient and community in the context of enhancing the overall functioning of each. Although there is a learning curve, applying the ICF codes allows the promotores to manage and track important outcomes, demonstrating the value of their work. Finally, we continue to grapple with the tensions inherent in multiple objectives: reach and intensity, allocation of resources for clinical and community impact, and evaluation by the health system and person-centered outcomes. We are in the early stages of a learning process that is teaching us to be humble but is also revealing glimpses of a different future in which communities and the health system co-create the conditions for both to flourish.

We thank Carmen Sanchez for her invaluable assistance with our data needs for this project.

\section{References}

1. Kark S. From medicine in the community to community medicine. JAMA 1974;228:1585-6.

2. The Folsom Group. Communities of solution: the Folsom Report revisited. Ann Fam Med 2012;10: 250-60.

3. Geiger HJ. Community-oriented primary care: a path to community development. Am J Public Health 2002;92:1713-6.

4. Roberts DW. Health is a community affair. Preview of the final report of the National Commission on Community Health Services. JAMA 1966;196: 332-3.

5. World Health Organization Europe. Declaration of Alma-Ata. 1978. Available from http://www.who.int/ publications/almaata_declaration_en.pdf. Accessed March $11,2013$.

6. Gillam S. Is the declaration of Alma Ata still relevant to primary health care? BMJ 2008;336:536-8.

7. Nutting PA. Community-oriented primary care: from principle to practice. Washington, DC: U.S. Government Printing Office; 1987.

8. Taylor EF, Lake T, Nysenbaum J, Peterson G, Meyers D. Coordinating care in the medical neighborhood: critical components and available mechanisms. White paper. AHRQ publication no. 11-0064. Rockville, MD: Agency for Healthcare Research and Quality; 2011.

9. Jaén CR, Ferrer RL, Miller WL, et al. Patient outcomes at 26 months in the patient-centered medical home National Demonstration Project. Ann Fam Med 2010;8(Suppl 1):S57-67; S92. 
10. Kaufman A, Galbraith P, Alfero C, et al. Fostering the health of communities: a unifying mission for the University of New Mexico Health Sciences Center. Acad Med 1996;71:432-40.

11. Kaufman A, Powell W, Alfero C, et al. Health extension in New Mexico: an academic health center and the social determinants of disease. Ann Fam Med 2010;8:73-81.

12. Institute of Medicine. Primary care and public health: exploring integration to improve population health. Washington, DC: National Academies Press; 2012.

13. Health Collaborative. 2010 Bexar County community health assessment. Available from: http:// www.healthcollaborative.net/index.php?option $=$ com_ content\&view $=$ article\&id $=68 \&$ Itemid $=136 . \quad$ Accessed August 1, 2012.

14. Wade DT, Halligan PW. Do biomedical models of illness make for good healthcare systems? BMJ 2004; 329:1398-401.

15. Backman CL. Outcome measures for arthritis care research: recommendations from the CARE III conference. J Rheumatol 2006;33:1908-11.

16. Steiner BD, Denham AC, Ashkin E, Newton WP, Wroth T, Dobson LA. Community Care of North Carolina: improving care through community health networks. Ann Fam Med 2008;6:361-7.

17. Nielsen M, Langer B, Zema C, Hacker T, Grundy P. Benefits of implementing the Patient-Centered Primary Care Medical Home: a review of cost and quality results, 2012. Washington, DC: PatientCentered Primary Care Collaborative; 2012. Available from http://www.pcpcc.net/sites/default/files/ media/benefits_of_implementing_the_primary_care_ pcmh.pdf. Accessed 26 March 2013.

18. Syme SL. Social determinants of health: the community as an empowered partner. Available at www. cdc.gov/pcd/issues/2004/jan/03_0001.htm. Accessed August 15, 2012.

19. Rosenthal EL, Wiggins N, Ingram M, MayfieldJohnson S, De Zapien JG. Community health workers then and now: an overview of national studies aimed at defining the field. J Ambul Care Manage 2011;34:247-59.

20. Joshu CE, Rangel L, Garcia O, Brownson CA, O'Toole ML. Integration of a promotora-led selfmanagement program into a system of care. Diabetes Educ 2007;33(Suppl 6):151S-8S.

21. Balcazar H, Alvarado M, Cantu F, Pedregon V, Fulwood R. A Promotora de Salud model for addressing cardiovascular disease risk factors in the US-Mexico border region. Prev Chronic Dis 2009;6:A02.

22. World Health Organization. International classification of functioning, disability and health. Geneva: World Health Organization; 2001. Available from http://www.who.int/classifications/icf/en/. Accessed March 11, 2013.

23. Jelsma J. Use of the International Classification of Functioning, Disability and Health: a literature survey. J Rehabil Med 2009;41:1-12.
24. Mold JW, Blake GH, Becker LA. Goal-oriented medical care. Fam Med 1991;23:46-51.

25. Beach MC, Inui T. Relationship-centered care. A constructive reframing. J Gen Intern Med 2006; 21(Suppl 1):S3-8.

26. Maynard DW. Social actions, gestalt coherence, and designations of disability: lessons from and about autism. Soc Probl 2005;52:499-524.

27. Schegloff EA. Analyzing single episodes of Interaction: an exercise in conversation analysis. Soc Psych Q 1987;50:101-14.

28. Bois Du JW. The stance triangle. In: Englebretson $\mathrm{R}$, ed. Stancetaking in Discourse: Subjectivity, Evaluation, Interaction. Amsterdam: John Benjamins Publishing; 2007:139-82.

29. TAI Human Research Inc. ICF illustration library [homepage]. Available from http://www.icfillustration. com. Accessed August 15, 2012.

30. Lorig KR, Ritter P, Stewart AL, et al. Chronic disease self-management program: 2-year health status and health care utilization outcomes. Med Care 2001;39:1217-23.

31. Patient-Centered Primary Care Collaborative. Joint principles of the patient centered medical home. Available from http://www.pcpcc.net/content/jointprinciples-patient-centered-medical-home. Accessed August 15, 2012.

32. Baskerville NB, Liddy C, Hogg W. Systematic review and meta-analysis of practice facilitation within primary care settings. Ann Fam Med 2012;10:63-74.

33. Taylor EF, Machta RM, Meyers DS, Genevro J, Peikes DN. Enhancing the primary care team to provide redesigned care: the roles of practice facilitators and care managers. Ann Fam Med 2013;11:80-3.

34. Nutting, PA, Crabtree. BF, Miller, WL, Stange, KC, Stewart EE, Jaen CR. Transforming physician practices to patient-centered medical homes: lessons from the National Demonstration Project. Health Aff (Millwood) 2011;30:439-45.

\section{Appendix}

First Nosotros: Group Visit (August 17, 2012)_Identify Body Functions and Structures Affected by Disease; Pressing Needs

In his late 20s, J is a Hispanic man with a spinal cord injury (s120) who came in a wheelchair (b760, s740, s750). He has struggled for 2 years with a decubitus ulcer (s8103) that has evolved into osteomyelitis (b435). He has deep vein thrombosis (b4303), swollen legs, and is running fevers at night. He takes several medications for these problems and gets nursing care for his ulcer off and on. He has problems with his bladder, which are treated with medicines (d53), and has been diagnosed with depression but refuses to take antidepressants (b117, b126, b130, b140, b152). 
What we want to happen: get to know each other. What we were able to do: identify body parts affected by disease using cards with drawings and listing current therapies and medications; plan to meet at the cafeteria in 2 days.

\section{Second Nosotros. Clinic's Cafeteria (August 19,} 2012)—Identify Activities and Participation Impairments (d) (Graded 1-4); Pressing Needs Originally from Mexico, J was a migrant agricultural worker who 8 years ago took on a roofing job during winter, fell from a second-story house, broke his back, and became paralyzed from the waist down. Since then he gets around in a battered wheelchair (d430-2, d45-4, d4551-4, d4552-4). His immediate family is far away and unable to visit or take care of him (d660-2). He has been renting a small house with other immigrant men. He is responsible for paying the electricity bill and has no money to pay this month's bill (d620-2, d870-2). Unable to work in the fields after the accident, he sought a job where he was required to sit for long hours in his wheelchair (d465-1). After the ulcer developed (d5702-2), he quit and began selling iron address signs in the street but has been less able to do so as his health deteriorated (d850-2). J has a seventh grade formal education from Mexico (d825-2) and has not taken classes since then. He complains about his bladder therapy not working (d53, d5702-2) and having urine leaks. He contemplated suicide some weeks ago and was seen by behavioral health (d2403 ). We agree that he is frustrated, impatient, distrustful, and uncertain about his care (d5702-2), and [he] makes little eye contact (d1-2, d5-2). He speaks limited English and has limited eligibility for services due to his immigration status (d950-2).

What we want to happen: obtain all information available to understand and support underlying healing processes in J's body and mind; avoid electricity to be shut down at home. What we were able to do: Make list of questions for the doctors about everything we want to know; plan for $\mathrm{J}$ to call the utility agency to accept delayed payment. 17th Nosotros. Avanza Community Center

(December 20, 2012)—Activities and Participation from Impairment (1-4), to Functioning (F) and Flourishing (N); Environmental Factors; Pressing Needs

$\mathrm{J}$ has acquired a new cushion for his wheelchair (d465-F, e1201) while becoming a member of a local medical equipment network (d9101-N). Referred by his PCP (e580) he is on antibiotic therapy with an infectious disease specialist, and in nursing care 3 times a week for his ulcer and osteomyelitis, which are very improved (no fevers or swelling); anticoagulant therapy is stable (e580, d5702-F); after some delay, he had a successful bladder surgery 6 weeks ago (e580) and has resolved his incontinence $(\mathrm{d} 53-\mathrm{F})$. J has aspirations of being a baker (the job where he got the ulcer was a bakery), and acquired skills as a baker's apprentice in Mexico (d825-F); this month he began baking Mexican cookies and pastries at home and selling them at his church and other places (d8500-N, d870-F, d930). The Avanza Community Center (e5850) granted him a scholarship to study for the GED and improve his English so he can continue developing his intellectual skills (d155-F, d825-F). He won a computer in a radio show (d9200) and learned how to use the Internet and E-mail (d360-N). He is assisting his roommates on how to use them (d660-F). We met with the Mexican consulate and found out J could qualify for Deferred Action, which allows immigrants that came as youth into the United States to work legally and a process was initiated (d950-3->1). He participated in holiday festivities (d9102).

What we want to happen: give some baked cookies to thank the Avanza staff as appreciation for their help; we want $\mathrm{J}$ to walk, to be a baker, and join a loved one in Mexico someday. What we were able to do: We looked for clinical trials that are investigating recovery from spinal cord injury; we gave a gift with heartfelt thanks; we built trust and respect in self and others. 